\title{
FREE LITERATURE/
}

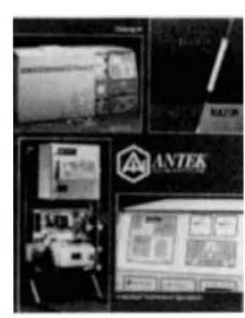

Equipment. Antek Instruments (Houston, TX) introduces a 32-page catalogue featuring their elemental analyzer for nitrogen and/or sulfur determinations. The unit performs total nitrogen and/or total sulfur analyses on gas, liquid, and solid samples in as little as one minute. The catalog also features sample handling equipment, data handling systems, autosamplers, application information, accessories, and consumables.

Write in 706 on Reader Service Card

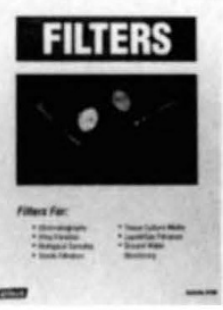

Filtration. A catalogue from Alltech (Deerfield, IL) gives information on over 450 filtration products for use in a variety of laboratory applications. Products include disposable syringe filters with a variety of membrane and housing types in both sterile and non-sterile versions. A variety of precut filtration membranes in diameters from $9 \mathrm{~mm}$ to $142 \mathrm{~mm}$ are offered.

Write in 707 on Reader Service Card

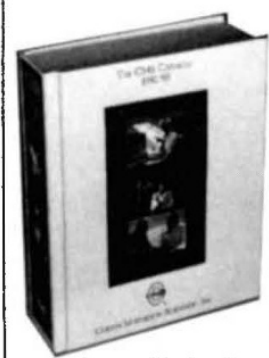

CMS. Curtin Matheson Scientific (Houston, TX) announces its 1992/93 catalogue, containing information on over 50,000 products from more than 400 suppliers serving clinical and industrial laboratories. Color tabs and indexes direct the reader to a chosen section; page headlines move the reader quickly through the product offerings, and product names and bullets at the beginning of text help differentiate between similar products.

Write in 708 on Reader Service Card

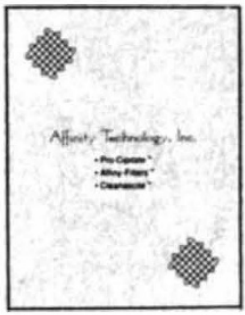

Product Lines. A brochure describes Affinity Technology's (New Brunswick, NJ) three product lines; ProCipitate, a polymeric reagent that can be used in the isolation of nucleic acids, glycoproteins, and viruses; Affiny-filter cartridges that provide an efficient method for affinity based separations; and Cleanascite, employed in the purification of antibodies from ascites fluid and cell culture.

Write in 709 on Reader Service Card

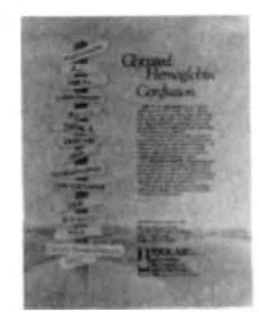

Confusion. Isolab (Akron, OH) offers the Glycohemoglobin Confusion brochure to give background information on $\mathrm{GHb}$ assays. Which assays give the most accurate measurement of blood glucose control is also discussed. As the importance of accurately monitoring diabetic control grows with every new study reported, physicians, lab technicians, and hospital managers need straight, simple answers to the growing $\mathrm{GHb}$ confusion.

Write in 711 on Reader Service Card

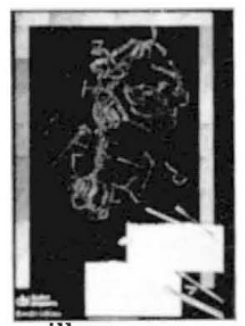

Poster. A colorful poster that aids in the selection of Brownlee HPLC columns is now available from Applied Biosystems (Woolston, U.K.). The $24^{\prime}$ X $36^{\prime}$ poster illustrates a protein molecule outlined by the 20 amino acids with their molecular weights. Guidelines for selecting columns by molecule and molecular weight are listed at the bottom of the chart.

Write in 701 on Reader Service Card

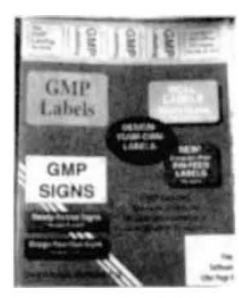

Labels. From GMP Labeling (Redwood City, CA) comes a compliance manual describing the company's regulatory compliance identification systems. Included in the fullcolor manual are labels and signs, as well as information on design-yourown label and sign kits. Introduced are pin-feed label series and GMPrint software. Together they generate multiple copies of labeling quickly and accurately with a few strokes on the computer keyboard.

Write in 710 on Reader Service Card

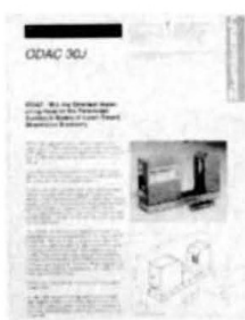

Diameter and Width Gauge. A detailed technical bulletin is offered by Zumbach Electronic (Mount Kisco, NY) describing design characteristics, specifications, and applications of their non-contact diameter-measuring gauge. The unit features high accuracy and reliability in a compact format. It will perform well even under very hostile environmental conditions.

Write in 704 on Reader Service Card

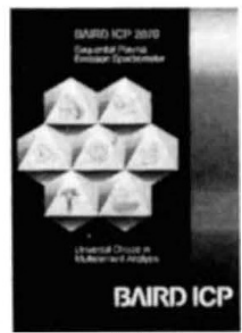

Plasma Emission Spectrometer. From Baird (Zoeterwoude, the Netherlands) comes a brochure describing the principal application and operating features of its sequential plasma emission spectrometer. Detailed specifications are also given in a supplemental data sheet. The unit's innovations include a directly accessible counter-top data station having extensive software and a mouse-driven graphical user interface.

Write in 702 on Reader Service Card 